\title{
Injectable Bone Substitute Paste Based on Hydroxyapatite, Gelatin and Streptomycin for Spinal Tuberculosis
}

\author{
Hendita Nur Maulida ${ }^{1, *}$, Dyah Hikmawati², Aniek Setiya Budiatin ${ }^{3}$ \\ ${ }^{1}$ Biomedical Engineering Study Program, Faculty of Science and Technology, Universitas \\ Airlangga, Surabaya, Indonesia \\ ${ }^{2}$ Department of Physics, Faculty of Science and Technology, Universitas Airlangga, \\ Surabaya, Indonesia \\ ${ }^{3}$ Department of Clinical Pharmacy, Faculty of Pharmacy, Universitas Airlangga, Surabaya, \\ Indonesia \\ *Corresponding author: henditamaulida@gmail.com
}

\begin{abstract}
World Health Organization (WHO) in 2005 reported that cases of tuberculosis (TB) in the world occur more than 8 million annually and 5-10\% were attacked in spine. The most effective treatment of spinal TB is evacuation of infected bone segments and fill with bone graft. It has been synthesized and characterized of injectable bone substitute (IBS) paste based on hydroxyapatite, gelatin and streptomycin. IBS paste synthesized by mixing hydroxyapatite and gelatin 20\% w/v with 75:25, 70:30, 65:35 and 60:40 ratio and streptomycin $10 \mathrm{wt} \%$. The mixture was then added with hydroxypropyl methylcellulose (HPMC) 4\% w/v as suspending agent. In vitro characterization performed include acidity (pH), injectability test, setting time, cytotoxicity (MTT assay) and microbacterium test. Acidity test results indicate a fourth variation of the samples had $\mathrm{pH}$ values approaching normal body $\mathrm{pH}(7,3$ to 7,6$)$ and is able to maintain stability when measured in 7 days. Injectability test results indicate IBS paste is injectable with the highest percentage of the injectability value at $97,74 \% \pm 0,19 \%$. IBS paste has been setting within 30 minutes to 1 hour when injected on hydroxyapatite scaffold that resembles the bone cavity and is able to cover the pore scaffold seen from the Scanning Electron Microscope (SEM). Scaffold pore size is smaller from range of 780,8 to $835,4 \mu \mathrm{m}$ into $225,2 \mu \mathrm{m}$. MTT assay results showed that IBS paste is not toxic and experiencing proliferation (viability $>100 \%$ ) that are expected to trigger osteoblast cell growth when applied. Microbacterium test results showed that IBS paste is an antibacterial seen from inhibition zone diameter of Staphylococcus aureus and has a high strengthsensitive antibacterial. Thus, hydroxyapatite, gelatin and streptomycin composites had qualified as injectable bone substitute which applied in cases of spinal tuberculosis.
\end{abstract}

Keywords: Spinal Tuberculosis, Injectable Bone Substitute, Hydroxyapatite, Gelatin, Streptomycin, Hydroxypropyl Methylcellulose

\section{INTRODUCTION}

Tuberculosis (TB) is an infectious disease caused by Mycobacterium tuberculosis which are systemic and can manifest in almost all organs of the body with the lungs as the primary infection site (Moesbar and Nazar, 2006). World Health Organization (WHO) in 2005 reported that TB cases in the world occur more than 8 million per year and $34 \%$ of them 
occur in Southeast Asia, including Indonesia (WHO, 2005; Zuwanda and Raka, 2013). Indonesia is the 3rd largest contributor to cases of TB after India and China with every 4 minutes there was one patient who died and transmission occurs every 2 seconds (Moesbar and Nazar, 2006). The incidence of extrapulmonary TB occurs in $25-30 \%$ and $5-10 \%$ of which occur in the bones and joints and the most attacking in the spine. Bone $\mathrm{TB}$ cases is diagnosed when the symptoms have started after one year (Pramarta et., 2003).

Spinal infection by TB could potentially cause serious morbidity including neurological deficits and permanent spinal deformity. Handling of spinal TB in general is giving antituberculosis drugs, immobilization using gips also orthopedic and neurological surgical intervention (Mehta and Bhujraj, 2001). Surgical intervention will be taken when after 3-4 weeks of antituberculosis drug administration and conservative therapy does not give a good response. In this case, the most effective spinal lesions treated with immediate surgery to evacuate TB bacteria, take the infected bone and fill the spinal segment involved with bone graft to promote healing and achieve spinal stability (Vitriana, 2002).

Commercially, the material that can be used as bone graft is hydroxyapatite (HA). Hydroxyapatite is a bioceramics material that is biocompatible and bioactive because of its mineral content, both physically and chemically very similar to bone (Warastuti and Basril, 2011). Hydroxyapatite can be obtained from the bones of mammals, fish bones, shells and other materials based on calcium phosphate. However, hydroxyapatite is brittle so that hard formed according to the required implant materials (Bramastya and Yusuf, 2013). Some researchers then developed a composite material of hydroxyapatite with polymers to improve the mechanical properties, one of which gelatin. Gelatin as a polymer derived from natural materials are biodegradable, biocompatible and non-toxic. Gelatin is widely used as space filler because it is easy to set up (Suryani et al., 2009).

Some use in orthopedics require injectable biomaterial graft which serves as a filler. Injectable system is ready to use, can follow the shape of bone cavity to be filled and polymerized in-situ after being injected. To produce composite injectable, it is required a gel as matrix material maker. Polymers are widely used came from the class of cellulose such as hydroxypropyl methylcellulose (HPMC) (Bramastya and Yusuf, 2013). HPMC is a water-soluble polymer and is widely used in the food industry as a thickening due to high viscosity (Rowe et al., 2009). Manufacture of injectable bone substitute (IBS) has been done by several researchers including Weiss et. al. (Weiss at al., 2007) with IBS based on calcium phosphate and Shen et. al. (Shen et al., 2014) with IBS based on alendronate and calcium phosphate.

In this study, we have been synthesized and characterized of IBS paste based on nanohydroxyapatite, gelatin and streptomycin for spinal TB cases. The use of nano-sized hydroxyapatite is expected to easily fit into the pores of the bones thoroughly. While the streptomycin is antibiotic, the primary antituberculosis drugs produced by the soil fungus Streptomyces griseus. This drug is 
readily soluble in water (Martindale, 2009). The main targets of streptomycin is working mechanism at the level of ribosome (Jawetz et al., 2007).

Characterization in this study include acidity test to determine degree of acidity of IBS to reach the body's normal $\mathrm{pH}$ and its stability as paste, injectability test to measure the ability of IBS can come out of injections, setting time to determine the time of IBS experience setting

\section{MATERIALS AND METHODS}

\section{Materials}

Tools used include digital scales Mettler Toledo, magnetic stirrer Yellow MAG HS 7, deep freezer, freeze dryer, thermometer, Terumo Syringe $12 \mathrm{ml}$ and $5 \mathrm{ml}$, glassware (vial bottles, beaker glass and petri dish), micrometers couplers, stopwatch, viscotester VT-04F RION, pH meter Benchtop OAKTON, Scanning Electron Microscope (SEM) FEI Inspect S50 Japan, a set of MTT Assay and microbacterium test.

Materials used include nano-hydroxyapatite of Barramundi fish from the National Nuclear

\section{Synthesis of Injectable Bone Substitute Paste}

IBS paste made in 4 variations in the composition of hydroxyapatite-gelatin that is 75:25, 70:30, 65:35 and 60:40 (w/w). Gelatin $20 \% \mathrm{w} / \mathrm{v}$ is dissolved in distilled water at $40^{\circ} \mathrm{C}$. Hydroxyapatite with variations in composition put into the gelatin solution then added streptomycin $10 \mathrm{wt} \%$ as a local dose (Budiatin et al., 2012). Meanwhile, HPMC $4 \% \mathrm{w} / \mathrm{v}$ is when injected, MTT Assay test to determine the citotoxicity of IBS when tested in fibroblast BHK-21 cells and microbacterium test to determine the IBS resistance against bacterial pathogens using S.aureus. These characterization are to evaluate the ability of hydroxyapatite, gelatin, and streptomycin as injectable bone substitute for spinal TB cases.

Energy Agency (BATAN) Jakarta, cow skin gelatin from 150 bloom Rousselot (Guangdong, China), streptomycin sulfate from PT. Meiji Indonesian Pharmaceutical Industries, hydroxypropyl methylcellulose (HPMC) from Sigma Aldrich, hydroxyapatite scaffold from Tissue Bank of Dr. Soetomo hospital Surabaya, Staphylococcus aureus, Trypticase Soy Broth (TSB) and microbiology nutrient agar from Merck.

dissolved in distilled water at $90^{\circ} \mathrm{C}$. Furthermore HPMC solution is added to a solution of gelatin, hydroxyapatite and streptomycin at $40^{\circ} \mathrm{C}$ and the mixture was stirred for six hours to produce a white IBS paste. 


\section{Acidity (pH) Test}

Acidity test is used to determine the degree of will automatically appear on the screen of $\mathrm{pH}$ acidity and the stability of IBS as paste when measured in 7 days. Measurement performed meter and make sure that the samples are measured at room temperature.

with placing electrodes into the sample and $\mathrm{pH}$

\section{Injectability Test}

Injectability conducted to evaluate the ability of IBS paste can come out of the injection within a certain time. IBS first measured the viscosity to ensure the applicable value as injectable system. Measurement results showing viscosity IBS in units dPa.s. Furthermore, injectability test performed using the reference method

reported by Shen et. al. (Shen et al., 2014). In this test, we used the syringe $12 \mathrm{ml}$ with inner diameter of $1,5 \mathrm{~cm}$ and needle with inner diameter of 1,2 $\mathrm{mm}$. Mass of IBS paste before and after injection within 2 minutes measured and its injectability calculated using the following equation

$$
\text { Injectability }(\%)=\frac{\text { mass expelled from the syringe }}{\text { total mass of the paste before injecting }} \times 100 \%
$$

Each test was repeated five times and the average value was calculated as a result of percentage of injectability.

\section{Setting Time}

Setting time testing was performed using hydroxyapatite scaffold that has been freezedried as a substrate (Putra and Alvian, 2014). Hydroxyapatite scaffold mass were measured to observe the changes that occur after setting. Testing was performed by injecting IBS samples into the scaffold vertically. Time

\section{Cytotoxicity Test with MTT Assay}

Cytotoxicity assay was performed using reagents MTT \{3- (4,5-dimethyl-2-thiazolil)2.5-diphenil-2H-tetrazolium bromide\} which comprises the step of culturing fibroblast Baby Hamster Kidney (BHK-21) cells, placing counting begins when IBS penetrated into the scaffold pores and stopped when the surface of the scaffold was completely dry and covered by the IBS. The test results also were observed using SEM to determine the surface morphology of microscopic scaffold in sizes below $200 \mathrm{~nm}$.

density can be determined using Elisa Reader and use equation (2) to calculate the percentage of living cells. Material is not-toxic if the percentage of living cells is more than 50\% (Spielmann et al., 2006). samples and reading the results. Optical cell

$$
\% \text { Living Cells }=\frac{O D \text { Treatment }+ \text { OD Media Control }}{O D \text { Cells Control }+ \text { OD Media Control }} \times 100 \%
$$

where : OD Treatment = optical density value of the sample after treatment

OD Cells Control = optical density value of the control cells

OD Media Control = optical density value of media control 
$\%$ Living Cells $\quad=$ the percentage of the number of cells after treatment

\section{Microbacterium Test}

Microbacterium test is used to determine the IBS resistance against bacterial pathogens by looking at the profile of bacterial inhibition zone diameter for several days. Culture of one ose Staphylococcus aureus (SA) suspended in 9 $\mathrm{mL}$ Trypticase Soy Broth (TSB) then cultured in incubator $60^{\circ} \mathrm{C}$ for 24 hours. Absorbance values of SA bacteria is calculated using UV-
Visible Spectrometer. Nutrient agar was prepared as a medium for bacteria. IBS paste put in wells agar medium with four repetitions and observed inhibition zone diameter after incubation for 24 hours. IBS strength levels against bacterial resistance was evaluated by comparing clear zone diameter according to Table 1 (Mutia et al., 2011).

Table 1. Strength Rate of Bacteria

\begin{tabular}{|c|c|}
\hline Clear Zone Diameter & Microorganism Resistance \\
\hline$>20 \mathrm{~mm}$ & Very Sensitive \\
\hline $10-20 \mathrm{~mm}$ & Sensitive \\
\hline $5-10 \mathrm{~mm}$ & Less Sensitive \\
\hline$<5 \mathrm{~mm}$ & Resistant \\
\hline
\end{tabular}

\section{RESULTS AND DISCUSSION}

\section{Acidity (pH) Test}

Degree of acidity $(\mathrm{pH})$ becomes one of the important factors to evaluate the performance of IBS material when applied. From the measurement results, we obtained an average

of HA-gelatin 75:25, 70:30, 65:35 and 60:40 $(\mathrm{w} / \mathrm{w})$ respectively is 7,$62 ; 7,54 ; 7,41$ and 7,35. Graph stability of IBS $\mathrm{pH}$ value can be seen in Figure 1. $\mathrm{pH}$ of each sample with variation composition

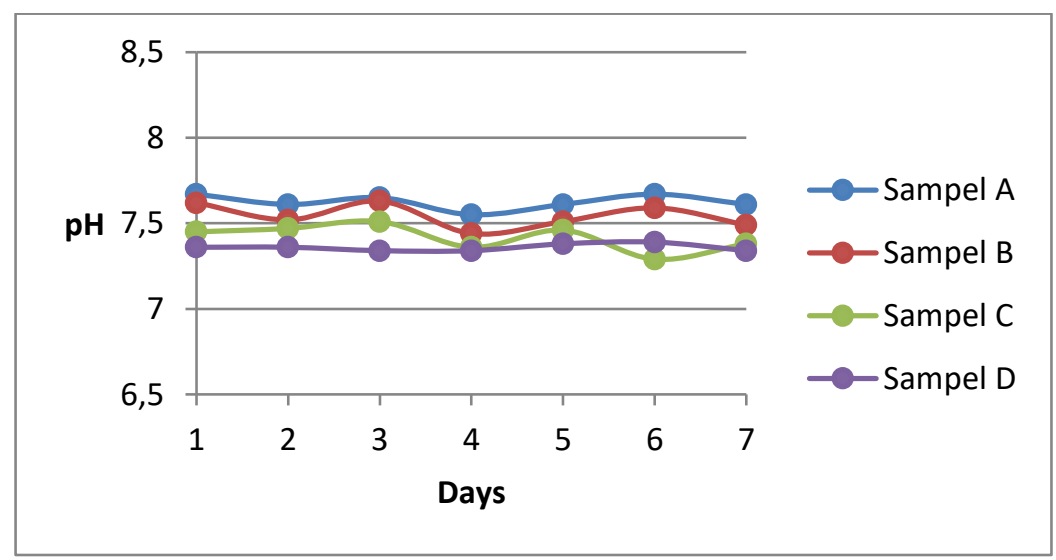

Figure 1. pH Value Stability of IBS Paste when Measured in 7 Days

IBS material requires $\mathrm{pH}$ more than 6 to be setting in bone. $\mathrm{pH}$ that is not too far from normal $\mathrm{pH}$ of around 7,8 (slightly alkaline conditions) can still be tolerated by the body
(Dorozkhin and Sergey, 2011).pH IBS samples were approaching the body's normal $\mathrm{pH}$ (about $6,8$ to 7,4$)$ are expected to have no pain effect in the bones when it is applied. 


\section{Injectability Test}

IBS paste viscosity values were measured using very good ability in terms of the percentage viscotester show number of $120 \mathrm{dPa} . \mathrm{s}$ and applicable in terms of injectability test results as shown in Figure 2. From the test results, it can be concluded that the four samples of IBS has a

results approaching $100 \%$. Best percentage of injectability owned by the sample $\mathrm{C}$ with HAgelatin ratio at $65: 35(\mathrm{w} / \mathrm{w})$ is equal to $97,74 \%$ $\pm 0,19 \%$.

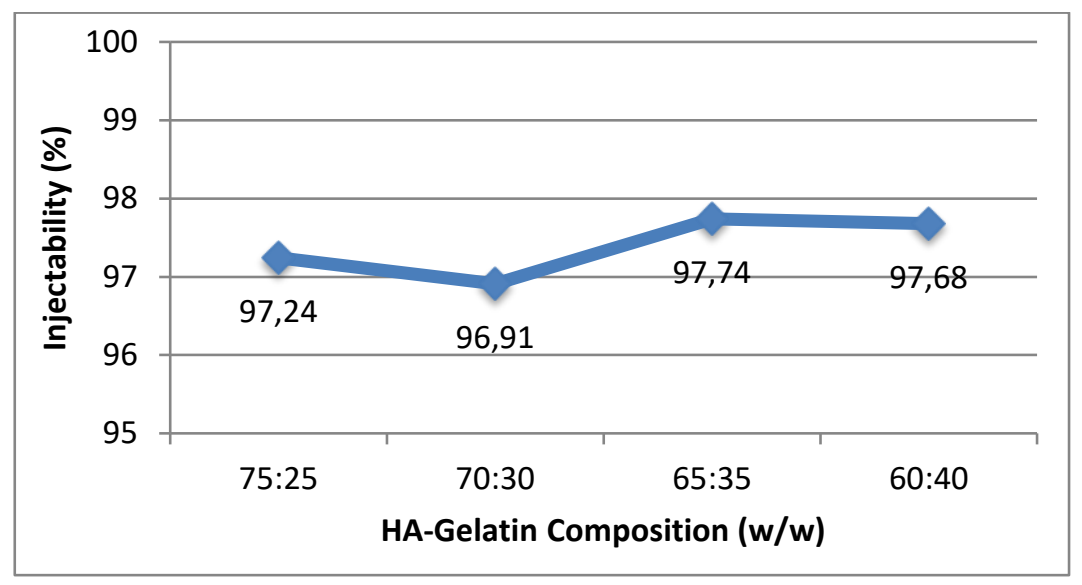

Figure 2. Injectability Testing Results of IBS Paste

\section{Setting Time}

Setting time performed using HA scaffold freeze-dried as a simulation of human bone parts. Media or substrates that have the same as the main constituent component of the sample will be able to trigger these components for neat and improve the crystallinity. From the test results, the final setting time raised about 30 minutes to 1 hour as shown in Figure 3.

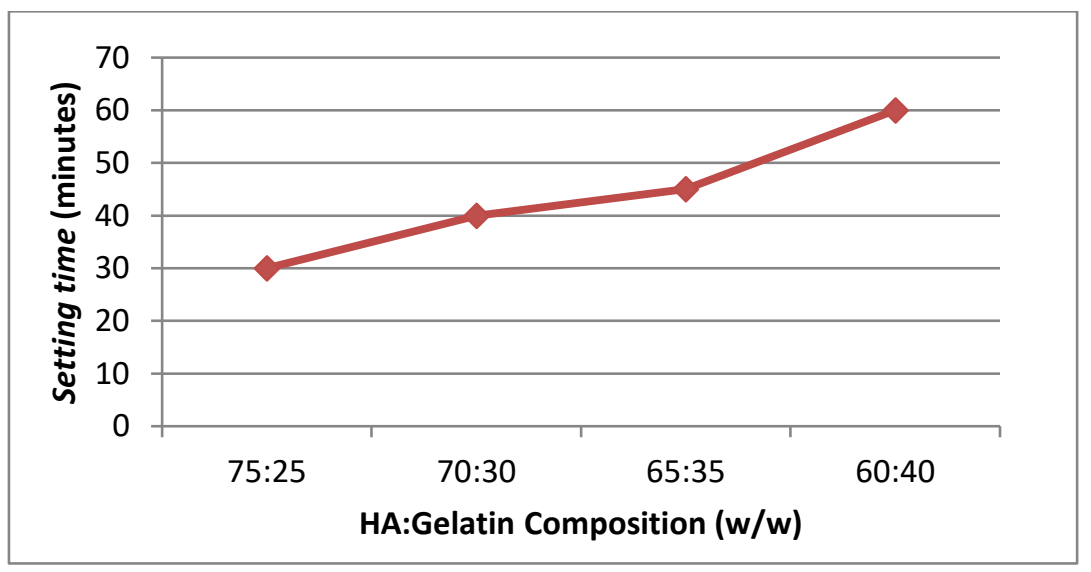

Figure 3. Setting Time Results of IBS Paste

Measurement results of mass scaffold before and after setting also showed an increase. This change is due to the scaffold HA synthesized by the method of freezedried is produce a pore that allows the IBS to infiltrate so that the crystallinity increases and pore seemed closed neatly. Changes in mass of the scaffold before and after setting surface microscopically analyzed using SEM as shown in Figure 4. 
From the scanning results, it appears that HA scaffold surface is covered evenly by IBS paste and the pores is smaller. The pore size before tested shows the distribution of values in the range of $780,8-835,4 \mu \mathrm{m}$ and after scaffold injected by IBS in the range of $225.2 \mu \mathrm{m}$. It might be concluded that the

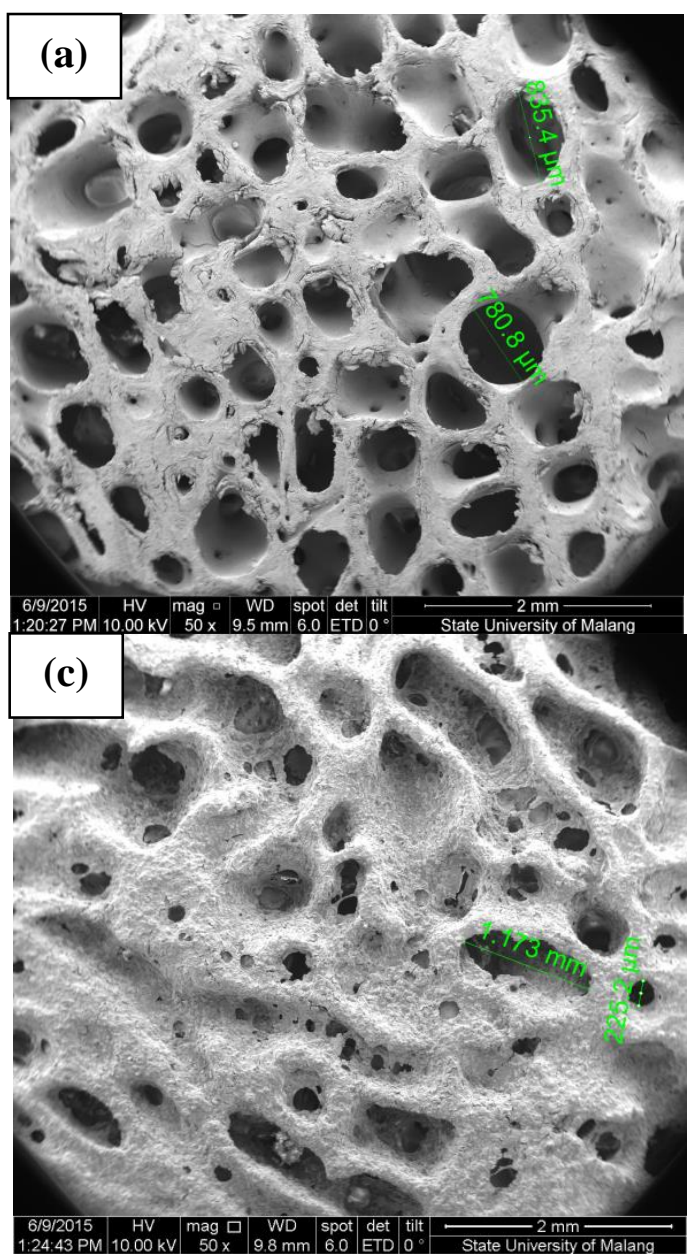

Figure 4. SEM of Scaffold HA Results (a) Before Injected with IBS Samples, Magnification at 50x (b) Magnification at 100x (c) After Scaffold HA injected with IBS Samples and Setting, Magnification at 50x (d)

Magnification at 100x
Magnication at 100x (c) After Scaffold HA injected with

IBS paste is able to evenly into the pores of the scaffold and bind hydroxyapatite in the vicinity so that crystallinity increases. Thus, IBS paste is able as bone substitution to fill the infected bone segments and vulnerable to further trigger the growth of new bone cells.
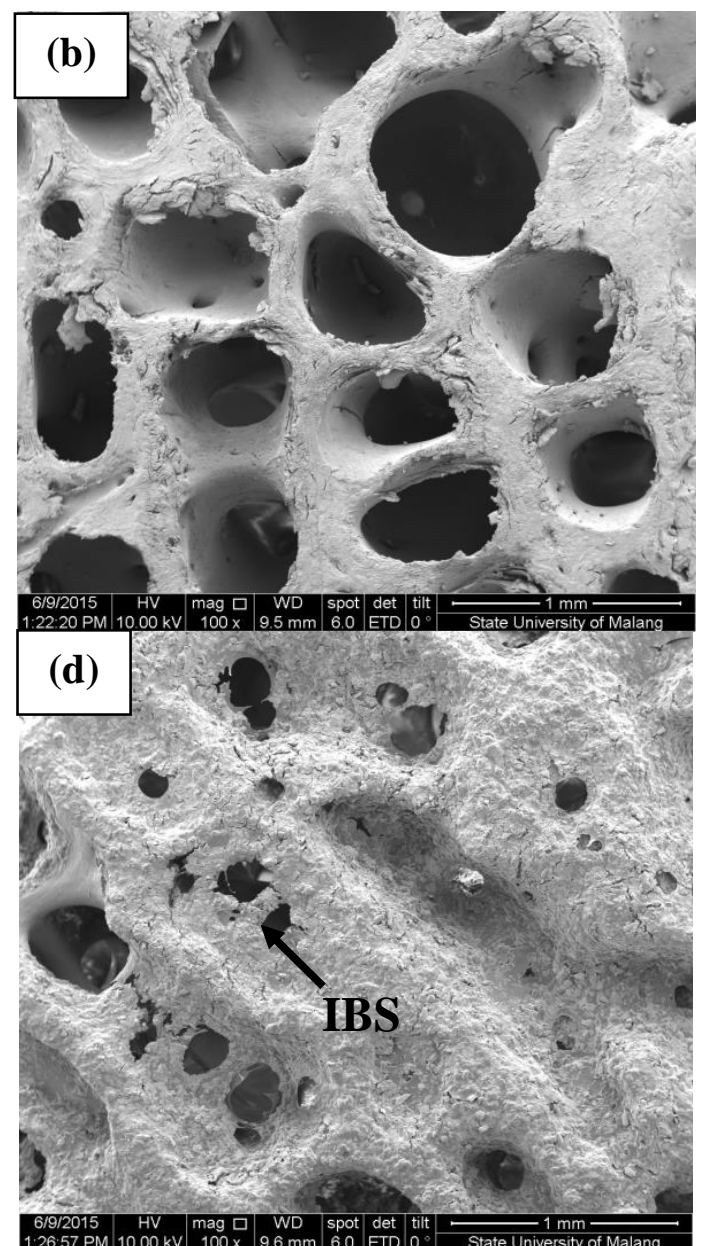

\section{Cytotoxicity Test with MTT Assay}

Each various samples of IBS tested in four repetitions and cell viability was calculated according to the equation (2) and then averaged as shown in Figure 5. From the test results, all sample variation of IBS is not-toxic seen from the percentage of cell viability which exceeds 50\% (Spielmann et al., 2006). There are several samples that have a percentage of cell viability of more than $100 \%$. This shows that fibroblast cells capable of undergoing proliferation in the sample so that it becomes greater than the control cells. Thus, it can be concluded that the IBS paste can become new cell growth media 
are also expected to be a medium for the growth

of osteoblast cells in bone when applied.

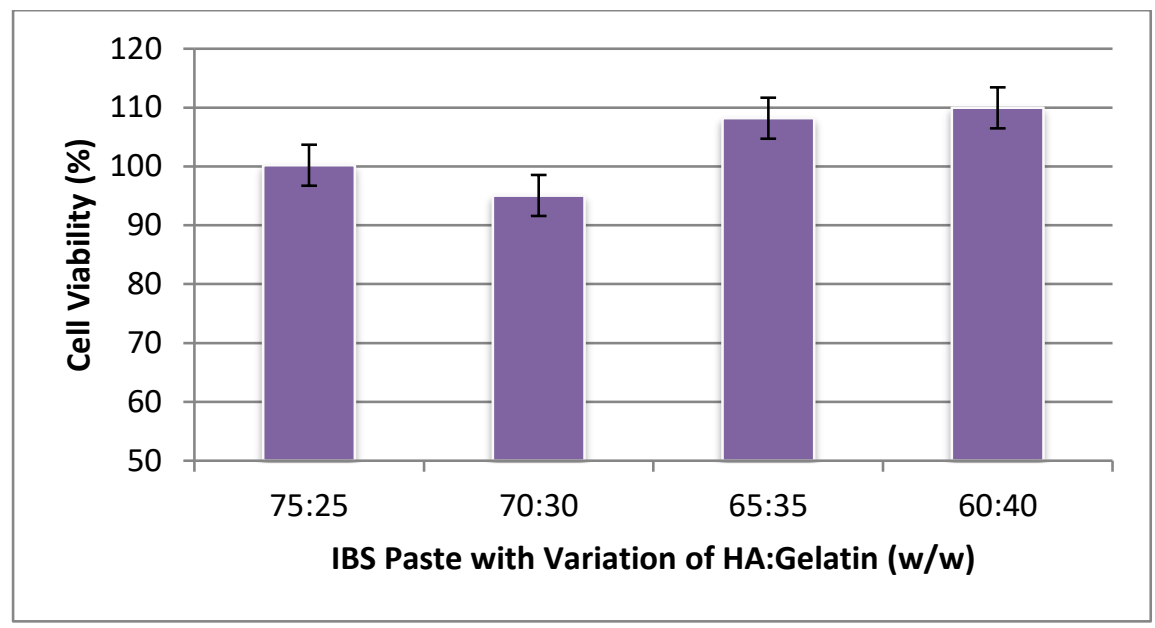

Figure 5. Cytotoxicity Test Results of IBS Paste

\section{Microbacterium Test}

Based on the test results, it is known that the diameter of 28-33 mm (Figure 6). This IBS paste is antibacterial seen from the area of inhibition zone diameter increased when inhibition zone around IBS discs with a incubated up to 3 days as shown in Figure 7.

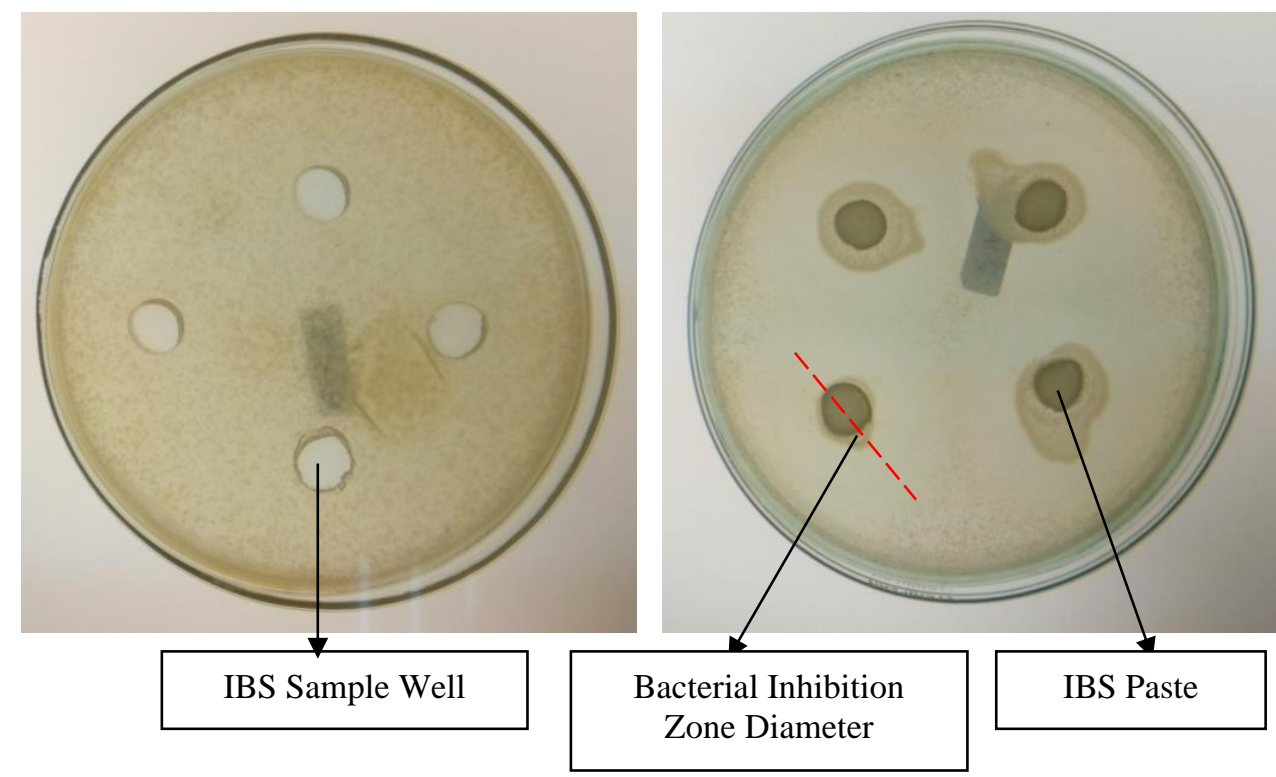

Figure 6. (a) Petri Without IBS, (b) Petri IBS with Bacterial Inhibition Zone Diameter 


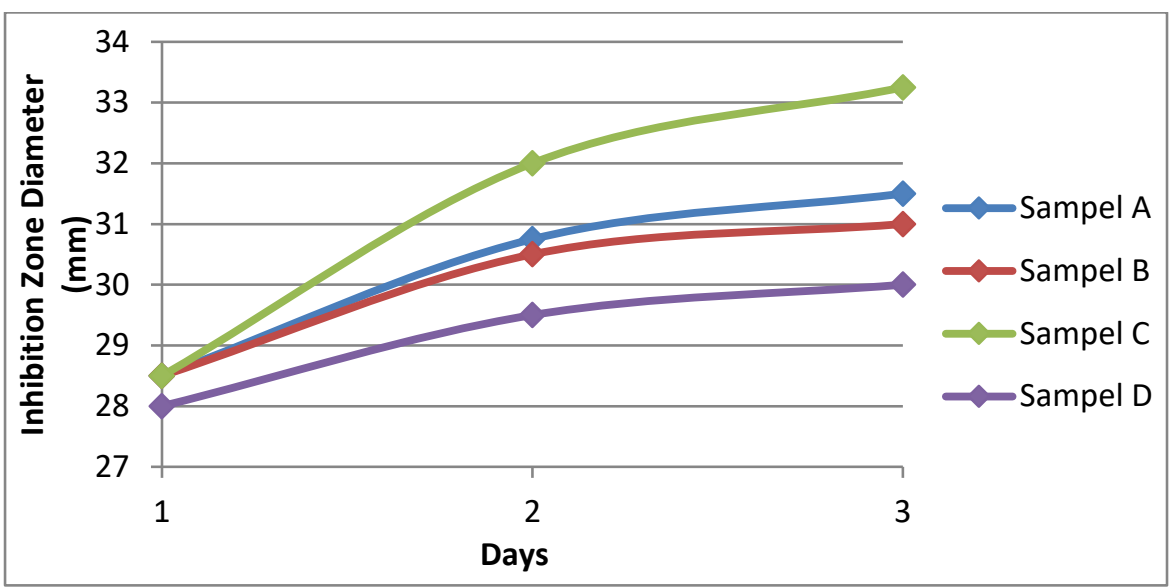

Figure 7. The Increase in Inhibition Zone Diameter Average of S.aureus Bacteria on IBS

The level of material strength against bacterial resistance can be evaluated by comparing the clear zone diameter by calculating the difference in bacterial inhibition zone diameter with a sample wells diameter. Obtained clear zone diameter test results in Table 2 . In addition to a bone filling material, IBS paste also expected to act as drug delivery systems to evacuate the TB bacterium that encourages faster healing and achieve early spinal stability.

Table 2. Clear Zone Diameter of IBS to Resistance Levels Against S. aureus After 24 Hours

\begin{tabular}{|c|c|c|c|c|}
\hline $\begin{array}{c}\text { IBS Paste at } \\
\text { Variation of } \\
\text { HA:Gel }(w / w)\end{array}$ & $\begin{array}{c}\text { Sample Wells } \\
\text { Diameter }(\mathrm{mm})\end{array}$ & $\begin{array}{c}\text { Inhibition Zone } \\
\text { Diameter }(\mathrm{mm})\end{array}$ & $\begin{array}{c}\text { Clear Zone } \\
\text { Diameter } \\
(\mathrm{mm})\end{array}$ & $\begin{array}{c}\text { Resistance } \\
\text { Level }\end{array}$ \\
\hline $75: 25$ & 9,0 & 28,5 & 19,5 & Sensitive \\
\hline $70: 30$ & 9,0 & 28,5 & 19,5 & Sensitive \\
\hline $65: 35$ & 9,0 & 28,5 & 19,5 & Sensitive \\
\hline $60: 40$ & 9,0 & 28,0 & 19,0 & Sensitive \\
\hline
\end{tabular}

\section{CONCLUSION}

1. In the physical characteristics, IBS paste has a $\mathrm{pH}$ value close to normal body $\mathrm{pH}$ (7,3 to $7,6)$ and is able to maintain stability when measured in 7 days. IBS paste is injectable with the highest percentage of injectability value at $97,74 \% \pm 0,19 \%$ and setting within 30 minutes to 1 hour when injected at HA

\section{REFERENCES}

Bramastya, Yusuf. 2013. Effect of Gamma Radiation on Mechanical Properties of UHMWPE-HAp Composite Results from Integrating Mechanical and Felts Heat To Tibial Tray. Bogor, scaffold that resembles the bone cavity and is able to cover the pore scaffold seen from the SEM results.

2. In the biological characteristics, IBS paste is not-toxic and it is antibacterial seen from inhibition zone diameter of S.aureus bacteria.
Indonesia: Bogor Agricultural Institute.

Budiatin Aniek Setiya, Muhamad Zaninuddin, Ferdiansyah, Fathia Rachmadani. 2012. Matrix Composites Bovine Hydroxyapatite-Gelatin Effectivity 
for Gentamicin Delivery System and

Regeneration Bone Defect. Surabaya,

Indonesia: Airlangga University.

Dorozkhin, Sergey V. 2011. Medical

Application of Calcium

Orthophosphate Bioceramics.

Moscow,

Russia.

DOI:10.5618/bio.2011.v1.n1.1.

Jawetz, Melnick, Adelberg. 2007. Medical Microbiology, Twenty-Fourth

Edition. USA: The Mc-Graw Hills

Companies, Pp. 209-216.

Martindale. 2009. The Complete Drug

Reference. Thirty-Sixth Edition.

United Kingdom: Pharmaceutical

Press London. ISBN 978085369840

1. ISSN 0263-5364.

Mehta J.S. and S.Y. Bhojraj. 2001.

Tuberculosis of The Thoracic Spine: A

Classification Based On The

Selection of Surgical Strategies.

India: Hinduja Hospital Mahim

Mumbai. The Journal of Bone and

Joint Surgery, Vol. 83-B, No. 6.

Moesbar, Nazar. 2006. Infection of

Tuberculosis in Spinal. Medan,

Indonesia: Departemen of Surgery,

Faculty of Medicine, University of

Sumatera Utara.

Mutia Theresia, Rifaida Eriningsih, Ratu

Safitri. 2011. Alginate Membrane as

Primary Wound Dressing and Drug

Delivery Media of Topical

Medications for Infected Wounds.

Bandung, Indonesia: Padjadjaran

University. Journal of Industry

Research. Vol. V, No.2, 2011, Pp.

161-174.
Paramarta I Gede Epi, Putu Siadi Purniti, Ida Bagus Subanada, Putu Astawa. 2008. Tuberculosis Spondylitis. Denpasar, Indonesia: Faculty of Medicine, Udayana University.

Putra, Alfian. 2014. Synthesis and Characterization of Composite Suspension of HydroxyapatiteGelatin with Addition Alendornate for Injectable Bone Substitute. Surabaya, Indonesia: Airlangga University.

Rowe Raymond C, Paul J. Sheskey, Marian E.

Quinn. 2009. Handbook Of Pharmaceutical Excipients, Sixth Edition. USA: Pharmaceutical Press, Pp. 326-329.

Shen Zhonghua, Tao Yu, Jiandong Ye. 2014. Microstructure and Properties of Alendronate-Loaded Calcium Phosphate Cement. Journal Elsevier. Materials Science and Engineering C 42 (2014) 303-311.

Spielmann Horst, Andrea Seiler, Susanne Bremer, Lars Hareng, Thomas Hartung, Hans Ahr, Elaine Faustman, Ulla Haas, Graeme J. Moffat, Heinz Nau, Philippe Vanparys, Aldert Piersma, Juan Riego Sintes and Jane Stuart. 2006. The Practical Application Of Three Validated In Vitro Embryotoxicity Tests. ATLA 34, 527-538.

Suryani Nelly, Farida Sulistiawati, Astri Fajriani. 2009. Type B Gelatin Gel Strength in Granule Formulation and its Mucoadhesive Characteristic. Jakarta, Indonesia: Syarif Hidayatullah University of Islam. 
MAKARA of Health Series, Vol 13,

No 1.

Vitriana, 2002. Tuberculosis Spondylitis.

Jakarta, Indonesia: Faculty of

Medicine, University of Indonesia.

Warastuti Yessy and Basril Abbas 2011.

Synthesis and Characterization of

Irradiated Injectable Bone Substitute

Paste Based on Hydroxyapatite. A

Scientific Journal for The

Applications of Isotopes and

Radiation, Vol. 7, No. 2. BATAN

Jakarta, Indonesia. ISSN 1907-0322.
Weiss Pierre, Olivier Gauthier, Jean-Michel Bouler, Gaël Grimandi, Guy Daculsi. 2007. Injectable Bone Substitute Using A Hydrophilic Polymer. France: Faculté de Chirurgie Dentaire.

WHO. Global Tuberculosis ControlEpidemiology, Strategy, Financing. WHO Report 2005. WHO/HTM/TB/2005.411.

Zuwanda and Raka Janitra. 2013. Diagnosis and Management of Tuberculosis Spondylitis. CDK-208, Vol. 40, No. 9. 